\title{
PT93, a novel caffeic acid amide derivative, suppresses glioblastoma cells migration, proliferation and MMP-2/-9 expression
}

\author{
KAISHU LI $^{1 *}$, YALIN TU $^{2,3^{*}}$, QINGYU LIU $^{1}$, YING OUYANG $^{1}$, \\ MINGLIANG HE ${ }^{1}$, MING LUO ${ }^{1}$, JINGKAO CHEN ${ }^{2,3}$, RONGBIAO PI ${ }^{2,3}$ and ANMIN LIU ${ }^{1}$ \\ ${ }^{1}$ Department of Neurosurgery, Sun Yat-Sen Memorial Hospital, Sun Yat-Sen University, Guangzhou, \\ Guangdong 510120; ${ }^{2}$ Department of Pharmacology and Toxicology, School of Pharmaceutical Sciences, \\ Sun Yat-Sen University, Guangzhou, Guangdong 510080; ${ }^{3}$ International Joint Laboratory (SYSU-PolyU HK) \\ of Novel Anti-Dementia Drugs of Guangdong, Guangzhou, Guangdong 510006, P.R. China
}

Received July 22, 2015; Accepted December 2, 2016

DOI: $10.3892 / \mathrm{ol} .2017 .5663$

\begin{abstract}
Glioblastoma multiforme (GBM) is the most malignant type of primary brain tumor in adults and can diffusely infiltrate adjacent normal tissue. GBM is therefore rarely cured by surgery or radiation therapy. Matrix metalloproteinases (MMPs) are involved in tissue remodeling and numerous other physiological progresses. The MMPs MMP-2 and MMP-9 are associated with the invasion ability of GBM. PT93 is a novel caffeic acid amide derivative that was first synthesized in 2013. In the present study, the human GBM T98G, U87 and U251 cell lines and the normal mouse neuron HT22 cell line were used to investigate the anticancer and cytotoxic effects of PT93 in vitro. The cytotoxicity of PT93 was measured using MTT and lactate dehydrogenase assays. The anti-proliferation effect was tested using a cell colony formation assay. Gelatin zymography analysis and a scratch test were used to investigate the anti-migration mechanism of PT93. Western blot analysis was used to measure the expression of MMP-2/-9. The experimental results showed that PT93 suppressed the proliferation of T98G cells, and showed cytotoxicity effects at high concentration in T98G, U87, U251 and HT22 cell lines. Furthermore, PT93 limited the migration ability of the cells and inhibited the extracellular MMP-2 and MMP-9 activity of T98G and U251 cells. Finally, the present study confirmed that PT93 affects the level of MMP-2/-9 expression in T98G cells in
\end{abstract}

Correspondence to: Dr Anmin Liu, Department of Neurosurgery, Sun Yat-Sen Memorial Hospital, Sun Yat-Sen University, 107 Yanjiang West Road, Guangzhou, Guangdong 510120, P.R. China E-mail: liuanmin@mail.sysu.edu.cn

${ }^{*}$ Contributed equally

Key words: caffeic acid amides, PT93, matrix metalloproteinases, glioblastoma multiforme a concentration-dependent manner. The present study indicates that PT93, as a novel caffeic acid amide derivative, may be used in the treatment of GBM.

\section{Introduction}

Glioblastoma multiforme (GBM), the most malignant and aggressive type of primary brain tumor in adults, accounts for $55 \%$ of all incidences of glioma (1). Due to the diffuse infiltration of tumor cells into normal brain tissue, local therapies such as surgery and/or radiation therapy are not effective. Subsequent to diagnosis, the median survival time of GBM is $12-15$ months $(2,3)$. As a result, preventing the invasion of cancer cells may improve the prognosis of glioma patients. Tumor invasion is considered to be a complicated process including the adherence of tumor cells to normal brain elements and the proteolysis of extracellular matrix (ECM) components (4). The ECM proteins that make up the specialized basement membrane (BM) serve as a barrier for cell invasion $(5,6)$. Furthermore, the degradation of the BM results in the release or activation of various growth factors required for angiogenesis, tumor growth and metastasis (3).

Matrix metalloproteinases (MMPs), a family of zinc-dependent endopeptidases, are known to serve important roles in the degradation of the BM and are associated with the invasion ability of glioma $(4,5,7)$. The MMPs MMP-2 and MMP-9 perform key roles in glioma progression and aggression $(8,9)$. Higher levels of MMP-2 and MMP-9 were observed in high-grade gliomas compared with non-invasive low-grade astrocytoma and normal brain tissue $(4,10)$. In the 1990s, following the identification of the important role of MMPs in cancer angiogenesis, growth and metastasis, MMPs became a therapeutic target for cancer treatment, which determined interest in the design and evaluation of matrix metalloproteinases inhibitors (MMPIs) as anticancer agents $(11,12)$. MMPs have been revealed to be important in regulating cellular activities and are involved in physiological and pathological processes $(13,14)$. The first generation of MMPIs, which had broad-spectrum MMP inhibition activity, 
caused unexpected side effects, including musculoskeletal pain and inflammation $(12,15,16)$.

Caffeic acid (CA) is a natural component of numerous plant-based foods including fruits, wine and coffee (17). In previous studies, CA was confirmed as a selective MMP-9 inhibitor with an anticancer effect (18-20). A series of CA derivatives have been synthesized, including CA phenethyl ester, which can selectively inhibit the activity of MMP-2/-9, but not MMP-1/-3/-7 (21). In 2013, Shi et al (22) synthesized a series of CA amide derivatives as MMPIs, including 3d. The present study synthesized 3d and termed it PT93 (Fig. 1A). The present study demonstrated that PT93 suppresses the proliferation and migration of $\mathrm{T} 98 \mathrm{G}$ and $\mathrm{U} 251$ cells, and revealed that PT93 inhibits MMP-2/-9 expression in T98G cells, which may contribute to the anticancer effect of the CA derivative.

\section{Materials and methods}

Materials, reagents and antibodies. Dimethyl sulfoxide (DMSO) and MTT were purchased from Sigma-Aldrich (Merck Millipore, Darmstadt, Germany). Dulbecco's modified Eagle's medium (DMEM) and fetal bovine serum (FBS) were obtained from Gibco (Thermo Fisher Scientific, Inc. Waltham, MA, USA). PT93 was synthesized in International Joint Laboratory (SYSU-PolyU HK) of Novel Anti-Dementia Drugs of Guangdong (Guangzhou, China) and dissolved in DMSO then stored at $-20^{\circ} \mathrm{C}$. Enhanced chemiluminescence (ECL) reagents were purchased from Landbiology (Guangzhou, China). A lactate dehydrogenase (LDH) assay kit was obtained from Nanjing Jiancheng Bioengineering Institute (Nanjing, China). MMP-2/9 rabbit primary antibodies (MMP-9 cat. no., BS1241; dilution, 1:1,000; MMP-2 cat. no., BS1236; dilution, 1:1,000) were purchased from Bioworld Technology, Inc. (St. Louis Park, MN, USA). $\beta$-actin primary antibody (cat. no., ACTN05 (C4); dilution, 1:5,000) was purchased from Thermo Fisher Scientific, Inc. Rabbit (cat. no., 32460; dilution, 1:1,000) and mouse (cat. no., 31430; dilution, 1:10,000) were goat derived IgG coupled to horseradish peroxidase and purchased from Thermo Fisher Scientific, Inc.

Chemistry. Acetic anhydride $(850 \mathrm{mg}, 8.33 \mathrm{mmol})$ was added to a chilled solution of CA (500 mg, $2.78 \mathrm{mmol})$ and 4-dimethylaminopyridine $(16.95 \mathrm{mg}, 138.77 \mu \mathrm{mol})$ in pyridine $(4 \mathrm{ml})$. The mixture was stirred at room temperature for $1 \mathrm{~h}$ and poured over crushed ice. The solution was acidified using $1 \mathrm{M}$ $\mathrm{HCl}(\mathrm{pH}<2)$, extracted with ethyl acetate (30 $\mathrm{ml} \times 2$ times), dried over anhydride sodium sulfate and filtered. The filtrate was concentrated by rotary evaporator yielding compound 1 as a white powder $(655 \mathrm{mg}, 87 \%)$, which was used directly in the next step without additional purification.

A total of $217.65 \mathrm{mg}(1.14 \mathrm{mmol})$ 1-ethyl-3-(3-dimethylaminopropyl) carbodiimide hydrochloride was added, at room temperature, to a mixture of compound 1 (200 mg, $756.91 \mu \mathrm{mol}), 2$-aminophenol $(165.2 \mathrm{mg}, 1.51 \mathrm{mmol})$ and trimethylamine $(314.76 \mu \mathrm{l}, 2.27 \mathrm{mmol})$ in anhydrous dichloromethane $(6 \mathrm{ml})$. The mixture was stirred at room temperature for $4 \mathrm{~h}$. The reaction was quenched by the addition of water (10 $\mathrm{ml})$ and extracted thrice with dichloromethane. The combined organic layers were washed with saline $(10 \mathrm{ml})$, dried over sodium sulfate, filtered and concentrated to remove the solvent. The resulting residue was purified by flash chromatography on silica gel (methanol/dichloromethane 1/50) yielding compound 3 as brown/yellow solid (150 mg, 73\%).

To a solution of compound $3(100 \mathrm{mg}, 281.42 \mu \mathrm{mol})$ in $4 \mathrm{ml}$ methanol, a solution of sodium carbonate $(59.65 \mathrm{mg}$, $562.84 \mu \mathrm{mol}$ ) in $3 \mathrm{ml} \mathrm{H}_{2} \mathrm{O}$ was added, and the mixture was stirred at room temperature for $1 \mathrm{~h}$. The solution was extracted with dichloromethane $(20 \mathrm{ml}$ at 3 time points) and the combined organic layers were washed with saline $(10 \mathrm{ml})$, dried over $\mathrm{Na}_{2} \mathrm{SO}_{4}$, filtered and concentrated to remove the solvent. The resulting residue was purified by flash chromatography on silica gel (methanol/dichloromethane 1/50-1/20) yielding PT93 as a yellow solid (51 mg, 66.8\%).Proton nuclear magnetic resonance (400 MHz, DMSO) $\delta 9.48(\mathrm{~s}, 4 \mathrm{H}), 7.83$ (d, J=7.8 Hz, 1H), 7.40 (d, J=15.5 Hz, 1H), 7.07-6.72 (m, 7H). Single peak at $254 \mathrm{~nm}$ and $215 \mathrm{~nm}$ in analytical high performance liquid chromatography (Fig. 1A and B).

Cell lines and cell culture. The human malignant GBM T98G, U87 and U251 cell lines and normal mouse neuron HT22 cells were purchased from Shanghai Institute of Biochemistry and Cell Biology (Shanghai, China). The cell lines were cultured and maintained in DMEM supplemented with $10 \%$ (volume of solute/volume of solution) x100 (volume percent) FBS and incubated at $37^{\circ} \mathrm{C}$ with $5 \% \mathrm{CO}_{2}$ humidified atmosphere. The cells were passaged subsequent to $80 \%$ fusion.

MTT assay and $L D H$ release assay. Cell viability was determined using MTT and LDH assays. The release of LDH in the culture medium was determined using a commercial kit. Following treatment with 0, 3, 10, 30, 100 and $300 \mu \mathrm{m}$ PT93 for $24 \mathrm{~h}$, the supernatant was drew from the media of per well and centrifuged at $400 \times \mathrm{g}(\mathrm{RCF})$ for $5 \mathrm{~min}$ at $4^{\circ} \mathrm{C}$, then $20 \mu \mathrm{l}$ supernatant was transferred into another 96-well microplate to determine LDH levels prior to adding MTT, according to the manufacturers protocol. The optical density was measured using a microplate reader (Omega Bio-Tek, Inc., Norcross, GA, USA) at $450 \mathrm{~nm}$. For the MTT assay, MTT ( $5 \mathrm{mg} / \mathrm{ml})$ was added to each well and the mixture was incubated for $2 \mathrm{~h}$ at $37^{\circ} \mathrm{C}$. The MTT reagent was then replaced with DMSO $(100 \mu \mathrm{l}$ per well) to dissolve the formazan crystals. Subsequent to the mixture being agitated at room temperature for $10 \mathrm{~min}$, absorbance was determined at $570 \mathrm{~nm}$ using a microplate reader (Omega Bio-Tek, Inc.). The samples without any drug were the control group. The results were expressed as the percentage absorbance of the control cells, which was set as $100 \%$. All experiments were performed in triplicate, $n=3$ per group.

Cell colony formation assay. T98G cells were seeded onto a 6-well plate at a density of 50-60 cells per well. The cells were maintained in DMEM containing $10 \% \mathrm{FBS}$ and 0,3 and $10 \mu \mathrm{m}$ PT93, and incubated at $37^{\circ} \mathrm{C}$ with $5 \% \mathrm{CO}_{2}$ humidified atmosphere for 1-2 weeks. The samples not administered any drug were the control group. After treated with PT93 for 1-2 weeks (w), cells was washed with PBS, then fixed with $5 \mathrm{ml}$ methanol for $20 \mathrm{~min}$ and stained with Giemsa staining solution for $30 \mathrm{~min}$. The stained cells were washed with PBS and air-dried, then observed using a low power lens. Colonies with $>50$ cells were counted. The results were expressed as the percentage of control group, which was set as $100 \%$. 
A

B<smiles>O=C(/C=C/c1ccc(O)c(O)c1)Nc1ccccc1O</smiles>

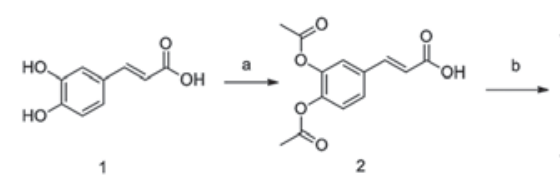

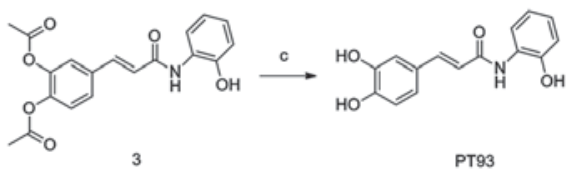

C
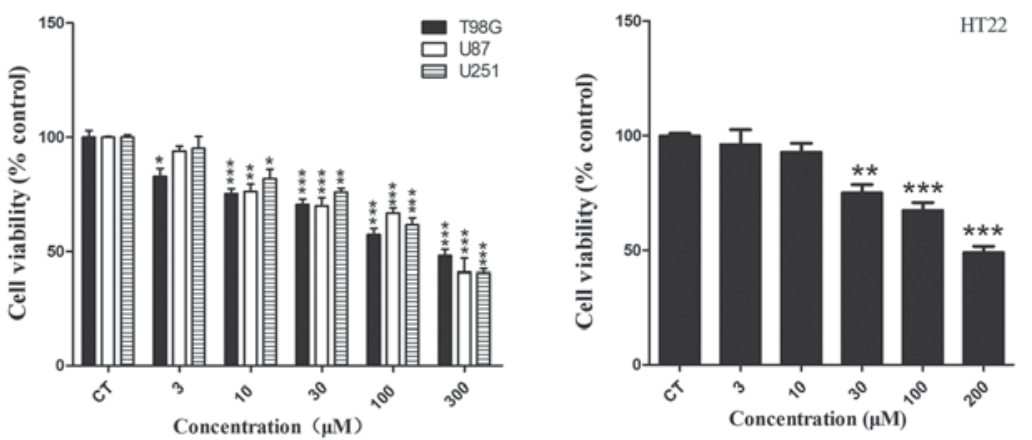

D

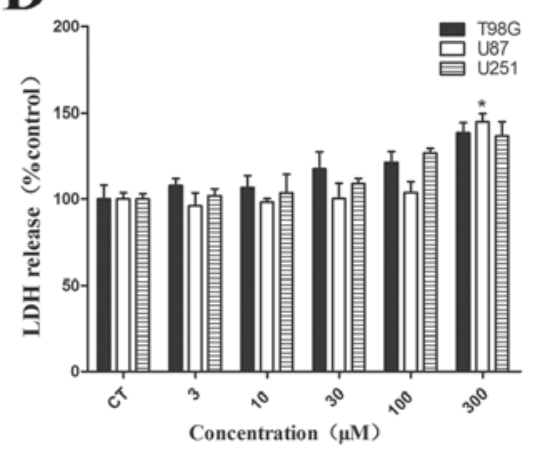

E a

b
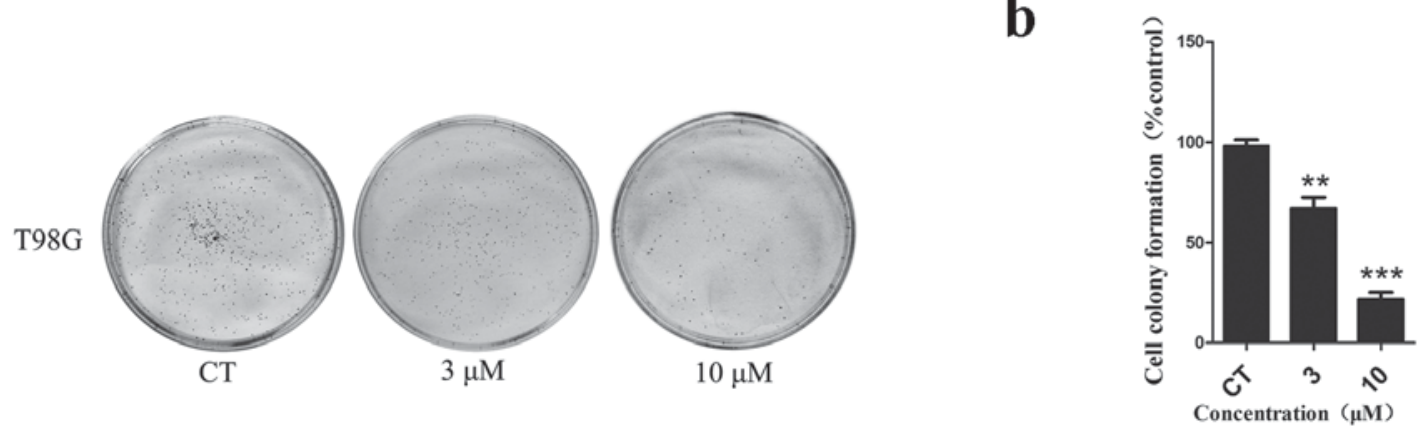

Figure 1. Chemical structure, synthetic routes, cytotoxicity and cell proliferative inhibition of PT93. (A) Chemical structure of PT93. (B) Synthetic routes of PT93. Reagents and conditions: (a) Acetic anhydride, 4-dimethylaminopyridine, pyridine, $0^{\circ} \mathrm{C}$ followed by room temperature; (b) 1-Ethyl-3-(3-dimethylamin opropyl) carbodiimide, triethylamine, dry dichloromethane, reacted at room temperature; (c) sodium carbonate, methonal/water, room temperature. (C) Cell viability (\%) of human GBM cell lines T98G, U87, U251 and normal neuron cell line HT22 treated with PT93 was assessed by a MTT assay. Subsequent to treatment with PT93, cell viability decreased in a dose-dependent manner and the concentration of inhibitor where inhibition is reduced by half (IC $\mathrm{I}_{50}$ ) was 300 , 272, 272 and $200 \mu \mathrm{M}$, respectively. (D) Although LDH release (\%) of GBM cells increased as concentration of PT93 increased, a significant difference was only observed at $300 \mu \mathrm{M}$ in U87 cells compared with the control group. (E) Proliferation of T98G cells was tested using a cell colony formation assay. T98G cells were treated with 0,3 and $10 \mu \mathrm{M}$ PT93 for 7 days. (a) The image is representative of 3 biological replicates. The colony formations were counted subsequent to 7 days. (b) The results show that PT93 can suppress T98G cell proliferation in a dose-dependent manner. ${ }^{*} \mathrm{P}<0.05,{ }^{* * *} \mathrm{P}<0.01$ and ${ }^{* * * *} \mathrm{P}<0.001 \mathrm{compared}$ with the control. GBM, glioblastoma multiforme; LDH, lactate dehydrogenase.

Scratch test. The cell migration ability was assessed by a scratch test. T98G and U251 cells were seeded onto a 6-well plate at a density of $2 \times 10^{5}$ cells $/ \mathrm{ml}$, and cultured at $37^{\circ} \mathrm{C}$ with $5 \% \mathrm{CO}_{2}$ humidified atmosphere for $24 \mathrm{~h}$. The linear scratch was made with a $200 \mu \mathrm{l}$ sterile pipette tip, and the cells were subjected to 0,3 and $10 \mu \mathrm{m}$ PT93 treatment. The samples not administered any drug were the control group. Subsequent to $24 \mathrm{~h}$, scratch wound healing was observed under an inverted microscope. The recovery distances of the scratches were compared with the control group.

Gelatin zymography analysis. The activity levels of MMP-2 and MMP-9 were estimated by gelatin zymography analysis. Cells were incubated with $0,1,3$ and $10 \mu \mathrm{m}$ PT93 in serum-free DMEM at $37^{\circ} \mathrm{C}$ for $24 \mathrm{~h}$. Then culture supernatants were collected and centrifuged at $356 \mathrm{x} g$ (RCF) for $10 \mathrm{~min}$ at $4^{\circ} \mathrm{C}$, and the supernatants were collected again. The cells not administered any drug were the control groups. MMP activity in the supernatant was measured using the MMP Zymography assay kit (Chemicon, Merck Millipore), according to the protocol of the manufacturer. The samples were separated by SDS-PAGE, under non-reducing conditions, using gels containing $10 \%$ gelatin and at $4^{\circ} \mathrm{C}$. Subsequent to electrophoresis, the gels were washed twice for 30 min each with solution A, then incubated with solution B for $10 \mathrm{~h}$. Finally, the gel was stained with Coomassie Blue R-250 (Bio-Rad Laboratories, Inc., Hercules, CA, USA). Clear bands indicating digested substrate were detected against a dark blue background, representing the areas of MMP activity. Bands were quantified using image quantitative analysis software (ImageJ 1.45, USA).

Cell extraction and western blotting. Cells were washed twice with ice-cold PBS and suspended in $80 \mu 1$ of lysis buffer (20 mM Tris-hydrochloride, $150 \mathrm{mM}$ sodium chloride, 1 mM EDTA, $1 \%$ Triton X-100, protease inhibitor cocktail, $2 \mathrm{mM}$ sodium orthovanadate and $10 \mathrm{mM}$ sodium fluoride, $\mathrm{pH}$ 7.5). The protein concentration was determined using a 
bicinchoninic acid assay kit (Pierce, Thermo Fisher Scientific Inc.). A total of $20 \mu \mathrm{g}$ protein was loaded in each lane. The proteins were separated using SDS-PAGE and electrically transferred to a polyvinylidene fluoride membrane (EMD Millipore). Subsequent to blocking the membrane with $5 \%$ skim milk, the target proteins were immunodetected using primary antibodies aforementioned in the reagents section. Following incubation with the secondary antibodies, the bands were detected by the enhanced chemiluminescence technique (Landbiology, Guangzhou, China).

Statistical analysis. All experiments described in the present study were repeated at $\geq 3$ time points. The data were presented as the mean \pm standard deviation. Statistical analyses between 2 groups were performed by unpaired Student's t-test. Differences among groups were tested by one-way analysis of variance following by a Tukey's test. $\mathrm{P}<0.05$ was considered to indicate a statistically significant difference.

\section{Results}

PT93 showed no significant cytotoxicity on GBM and normal neuron cell lines at low concentration. The structure and synthesis process of PT93 are demontrated in Fig. 1A and B. The inhibitory effect of PT93 on cell viability in human GBM T98G, U251, U87 cells and normal mouse neuron HT22 cells was measured using an MTT assay subsequent to $24 \mathrm{~h}$ exposure. A concentration-dependent inhibitive effect on cell viability was observed in the aforementioned 4 types of cell lines. As shown in Fig. 1C, the concentration of inhibitor where inhibition is reduced by half $\left(\mathrm{IC}_{50}\right)$ in T98G, U87, U251 and HT22 cells were 300, 272, 272 and $200 \mu \mathrm{M}$, respectively.

Furthermore, the present study tested the cytotoxicity effects of PT93 in T98G, U87, U251 cells using an LDH assay. No significant cytotoxicity was observed at low concentrations $(<30 \mu \mathrm{M})$ in T98G, U251 and U87 cells. As shown in Fig. 1C, although the level of LDH release of T98G, U251 and U87 cells increased at concentrations of 100 and $300 \mu \mathrm{M}$, a significant difference $(\mathrm{P}=0.0252)$ was only observed at $300 \mu \mathrm{M}$ in U87 cells.

PT93 inhibited the proliferation of T98G cells. The proliferative ability of the T98G cells was tested with a cell colony formation assay. The cells were treated with 0,3 or $10 \mu \mathrm{M}$ PT93 for 1 week and the results of cell colonies are shown in Fig. 1Ea and Eb. PT93 significantly $(\mathrm{P}=0.0051$ and 0.0007$)$ inhibited cell colony formation in a dose-dependent manner in T98G cells. The colony numbers decreased between $251 \pm 45$ and $200 \pm 26$ and $103 \pm 15$ when the cells were treated with 3 and $10 \mu \mathrm{M}$ PT93, respectively.

Scratch migration assay. A scratch migration assay was performed to confirm the influence of PT93 in the migration of T98G and U251 cells. T98G cells were treated with 0,3 and $10 \mu \mathrm{M}$ PT93 subsequent to a wound being made in the cell layer. In the scratch migration assay, PT93 inhibited the migration of T98G and U251 cells in a dose-dependent manner. PT93 significantly $(\mathrm{P}<0.05$ or $\mathrm{P}<0.001)$ limited the migration of the cell lines at 3 and $10 \mu \mathrm{M}$ (Fig. 2).
Gelatin zymography and western blotting assay. Gelatin zymography was used to test the level of MMP-2/-9 activity. Subsequent to the T98G and U251 cells being treated with PT93 at $0,1,3$ and $10 \mu \mathrm{M}$ for $24 \mathrm{~h}$, the supernatant was extracted to detect the activity of MMP-2 and MMP-9. The results revealed that $\mathrm{PT} 93$ significantly $(\mathrm{P}<0.01$ or $\mathrm{P}<0.001)$ decreased the level of MMP-2 and MMP-9 activity in a concentration-dependent manner (Fig. 3A and B). Western blot analysis was used to measure the level of MMP-2/-9 expression. The results demonstrated that PT93 suppresses MMP-2/-9 expression in a dose-dependent manner (Fig. 3C).

\section{Discussion}

The conventional treatments of GBM include surgery and radiotherapy, however the prognosis is extremely poor (23). Subsequent to the approval of temozolomide (TMZ) by the Food and Drug Administration in 1999, post-operative radiotherapy (RT) combined with TMZ chemotherapy has been developed as the standard therapy for newly diagnosed GBM (24). The median survival length subsequent to treatment with RT plus TMZ was 14.6 months compared with 12.1 months for RT alone $(10,23,25)$. Therefore, the exploration of novel agents that could be used alone or combined with TMZ to improve the outcome of GBM is required.

The present study investigated the effects of PT93 in GBM cell lines, examining cell viability, cytotoxicity, proliferation, migration and MMP inhibition. Firstly, the present study tested the inhibitory effect of PT93 on the cell viability of the GBM T98G, U87 and U251 cell lines, and the normal mouse neuron HT22 cell line, using an MTT assay. The MTT assay results showed that PT93 reduced cell viability in the 4 types of cell line in a dose-dependent manner (Fig. 1C). The $\mathrm{IC}_{50}$ in T98G, U87, U251 and HT22 was $300,272,272$ and $200 \mu \mathrm{M}$, respectively. Furthermore, the present study tested the cytotoxicity of PT93 in T98G, U87 and U251 cells using an LDH assay. The result of the $\mathrm{LDH}$ assay demonstrated that although the release of LDH increased as the concentration of PT93 increased, a statistically significant difference was only observed at $300 \mu \mathrm{M}$ in the U87 cell line $(\mathrm{P}<0.05)$. The results of the MTT and LDH assays suggested that cell viability reduced by PT93 may be associated with the inhibition of cell proliferation.

The present study tested the anti-proliferation effect of PT93 using a cell colony formation assay. PT93 exhibited potent inhibition of the colony formation of T98G cells. In contrast to the control group, PT93 significantly suppressed the proliferation of the T98G cells at concentrations of 3 and $10 \mu \mathrm{M}$ (Fig. 1D). The present then study investigated the effect of PT93 on the migration of T98G and U251 cells using a scratch test. Under low-serum conditions, PT93 significantly suppressed the migration of the aforementioned cells at concentrations of 3 and $10 \mu \mathrm{M}$ compared with the control group $(0 \mu \mathrm{M})$. Cell motility and MMPs are involved in the invasion ability of tumors. PT93 was reported as a selective MMP inhibitor, inhibiting MMP-2 and MMP-9 (22). A number of studies demonstrated that MMPs are associated with the ability of tumors to migrate and invade $(12,26,27)$. First generation MMPIs with broad-spectrum MMP inhibitory ability cause unexpected side effects, including musculoskeletal pain and inflammation $(12,15,16)$. 

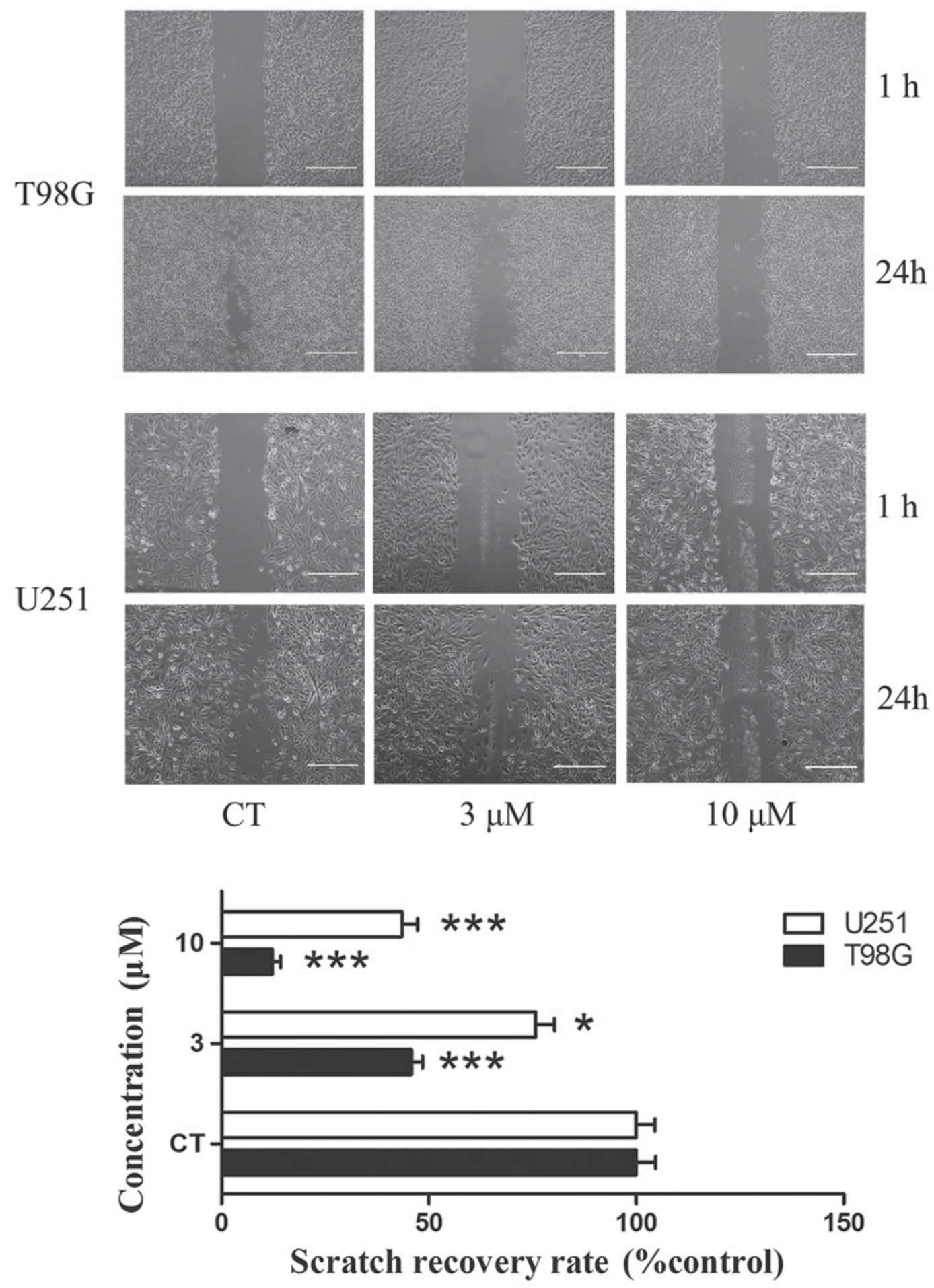

Figure 2. PT93 suppresses T98G and U251 cells migration ability. The cells were treated with PT93 at a concentration of 0,3 or $10 \mu \mathrm{M}$. Subsequent to $24 \mathrm{~h}$, scratch wound healing was observed and analyzed. The recovery rate of the scratch wound was measured subsequent to $24 \mathrm{~h}$. ${ }^{*} \mathrm{P}<0.05,{ }^{* * *} \mathrm{P}<0.01$ and ${ }^{* * * *} \mathrm{P}<0.001$ compared with the control.

Thus, MMPIs which selectively inhibit MMP-2/9 may suppress the migration of cancer cells and reduce the number of side effects. The present study hypothesized that the anticancer effect of PT93 in GBM cell lines may be associated with MMP inhibition, and confirmed this by treating the T98G cells with increasing concentrations of PT93 and testing the MMP activity using gelatin zymography. In the aforementioned analysis, the activity of MMP-2 and MMP-9, which were secreted by T98G and U251 cells, decreased as drug concentration increased. At
$10 \mu \mathrm{m}, \mathrm{PT} 93$ significantly suppressed extracellular MMP-2 and MMP-9 activity compared with the control group (Fig. 3A and B). Furthermore, the present study used western blotting to measure the expression of MMP-2/-9 in T98G. The results of the western blot analysis revealed that PT93 suppresses intracellular MMP-2 and MMP-9 expression. The authors infer that PT93 may also reduce the level of MMP-2/-9 secretion, potentially explaining why the CA derivative affects extracellular MMP-2 and MMP-9 activity. 
A

T98G

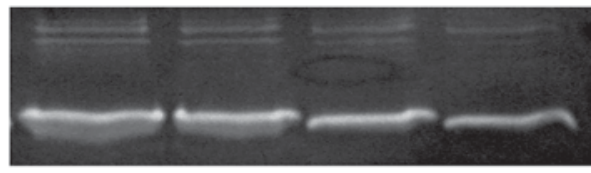<smiles>[CH-]C1CC1</smiles><smiles>C1#CCCC1</smiles><smiles>[C+]#CC</smiles>

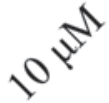

MMP9 MMP2
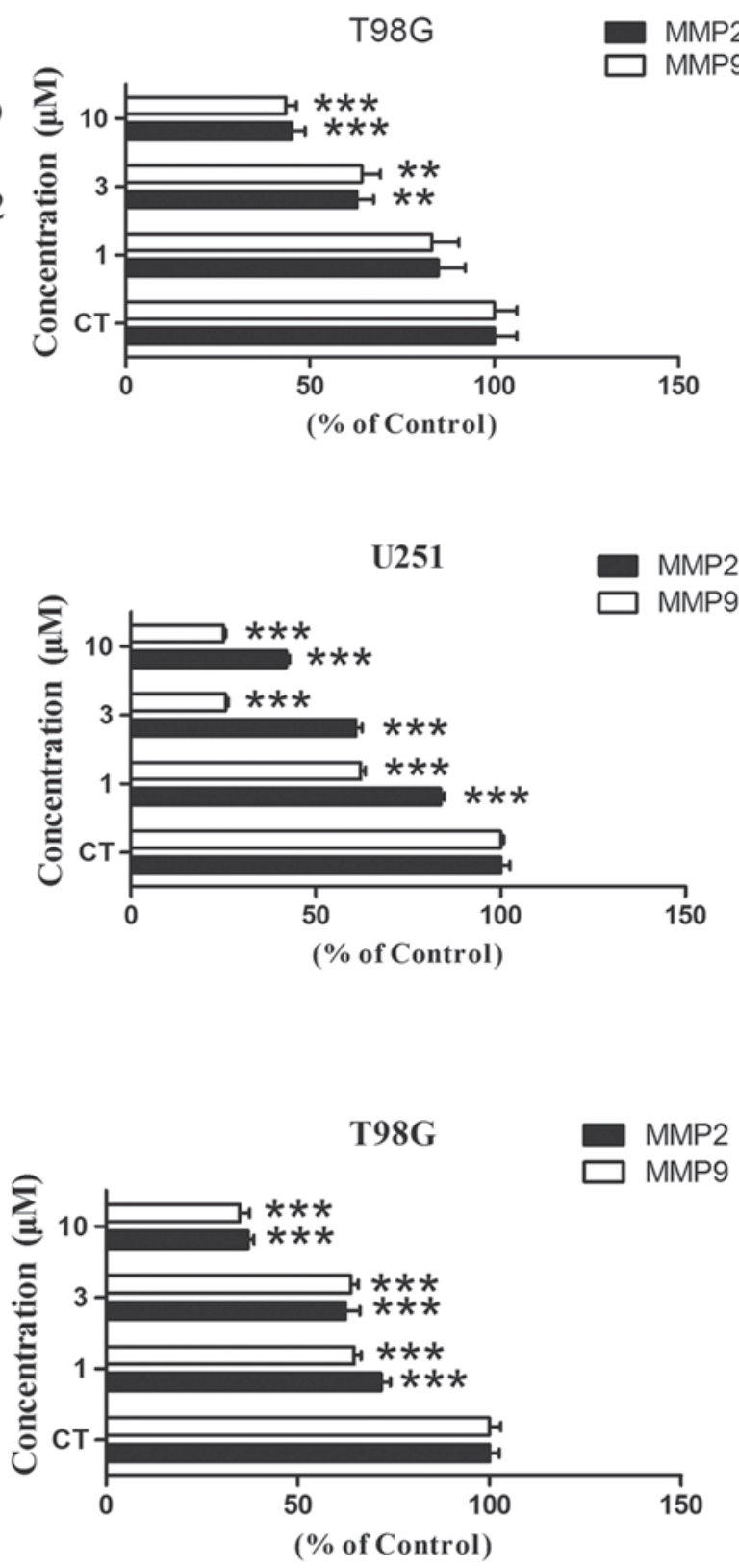

Figure 3. PT93 suppresses the expression of MMP-2/9 and activity of T98G and U251 cells. (A) Inhibition of MMP-2/-9 activity induced by PT93 in T98G cells at increasing concentrations. Extracellular activities of MMP-2/-9 were estimated by gelatin zymography analysis. There were significant differences of MMP-9 activity at concentrations of 3 and $10 \mu \mathrm{M}$ compared with the control. At 3 and $10 \mu \mathrm{M}$, MMP-2 activity was markedly reduced. (B) Inhibition of MMP-2/-9 activity induced by PT93 in U251 cells at increasing concentrations. Extracellular activities of MMP-2/-9 were estimated by gelatin zymography analysis. There were significant differences in MMP-2/-9 activity at 1,3 and $10 \mu \mathrm{M}$ compared with control. (C) Intracellular MMP-2/-9 expression was measured by western blot analysis in T98G cells. MMP-2/-9 expression was reduced as PT93 concentration increased. There were significant differences in MMP-2/-9 activity at 1,3 and $10 \mu \mathrm{M}$ compared with the control. ${ }^{* *} \mathrm{P}<0.01$ and ${ }^{* * *} \mathrm{P}<0.001$ compared with control. CT, control; MMP, matrix metalloproteinases.

The present study confirmed that the anticancer effect of PT93 was associated with the inhibition of the migration and proliferation of GBM cells, and the level of MMP-2/-9 expression. In contrast with first generation MMPIs, PT93 may exhibit fewer side effects. TMZ has been reported to inhibit the migration of U251 cells at a concentration of $100 \mu \mathrm{M}$ (24). Therefore, the effect of PT93 may combine with the effect of TMZ to enhance the anti-migration ability and reduce the invasiveness of GMB. PT93 exhibits potential in the treatment of GBM as a new generation MMPI.

\section{Acknowledgements}

The present study was supported by the Fundamental Research Funds for Guangdong Provincial Project of Science and Technology (grant nos. 2014A020212091, 2014A020212096 and 2016A020215061). 


\section{References}

1. Shi J, Sun B, Shi W, Zuo H, Cui D, Ni L and Chen J: Decreasing GSH and increasing ROS in chemosensitivity gliomas with IDH1 mutation. Tumour Biol 36: 655-662, 2015.

2. Baldock AL, Ahn S, Rockne R, Johnston S, Neal M, Corwin D, Clark-Swanson K, Sterin G, Trister AD, Malone H, et al: Patient-specific metrics of invasiveness reveal significant prognostic benefit of resection in a predictable subset of gliomas PLoS One 9: e99057, 2014.

3. Bellail AC, Hunter SB, Brat DJ, Tan C and Van Meir EG: Microregional extracellular matrix heterogeneity in brain modulates glioma cell invasion. Int J Biochem Cell Biol 36: 1046-1069, 2004.

4. Wang M, Yoshida D, Liu S and Teramoto A: Inhibition of cell invasion by indomethacin on glioma cell lines: In vitro study. J Neurooncol 72: 1-9, 2005.

5. Jacob A and Prekeris R: The regulation of MMP targeting to invadopodia during cancer metastasis. Front Cell Dev Biol 3: 4, 2015

6. Rao JS: Molecular mechanisms of glioma invasiveness: The role of proteases. Nat Rev Cancer 3: 489-501, 2003.

7. Alam S and Kelleher SL: Cellular mechanisms of zinc dysregulation: A perspective on zinc homeostasis as an etiological factor in the development and progression of breast cancer. Nutrients 4 : 875-903, 2012

8. Tian L, Zhang Y, Chen Y, Cai M, Dong H and Xiong L: EMMPRIN is an independent negative prognostic factor for patients with astrocytic glioma. PLoS One 8: e58069, 2013.

9. Lee EJ, Kim SY, Hyun JW, Min SW, Kim DH and Kim HS: Glycitein inhibits glioma cell invasion through down-regulation of MMP-3 and MMP-9 gene expression. Chem Biol Interact 185 18-24, 2010.

10. Levicar N, Nuttall RK and Lah TT: Proteases in brain tumour progression. Acta Neurochir (Wien) 145: 825-838, 2003.

11. Alcantara MB and Dass CR: Pigment epithelium-derived factor as a natural matrix metalloproteinase inhibitor: A comparison with classical matrix metalloproteinase inhibitors used for cancer treatment. J Pharm Pharmacol 66: 895-902, 2014.

12. Hadler-Olsen E, Winberg JO and Uhlin-Hansen L: Matrix metalloproteinases in cancer: Their value as diagnostic and prognostic markers and therapeutic targets. Tumour Biol 34: 2041-2051, 2013

13. Singh D, Srivastava SK, Chaudhuri TK and Upadhyay G: Multifaceted role of matrix metalloproteinases (MMPs). Front Mol Biosci 2: 19, 2015.

14. Yoshizaki T, Sato H and Furukawa M: Recent advances in the regulation of matrix metalloproteinase 2 activation: From basic research to clinical implication (Review). Oncol Rep 9: 607-611, 2002.
15. Dufour A and Overall CM: Missing the target: Matrix metalloproteinase antitargets in inflammation and cancer. Trends Pharmacol Sci 34: 233-242, 2013.

16. Vandenbroucke RE and Libert C: Is there new hope for therapeutic matrix metalloproteinase inhibition? Nat Rev Drug Discov 13: 904-927, 2014.

17. Liu RH: Health-promoting components of fruits and vegetables in the diet. Adv Nutr 4: 384S-392S, 2013

18. Park WH, Kim SH and Kim CH: A new matrix metalloproteinase-9 inhibitor 3,4-dihydroxycinnamic acid (caffeic acid) from methanol extract of Euonymus alatus: Isolation and structure determination. Toxicology 207: 383-390, 2005.

19. Chiang EP, Tsai SY, Kuo YH, Pai MH, Chiu HL, Rodriguez RL and Tang FY: Caffeic acid derivatives inhibit the growth of colon cancer: Involvement of the PI3-K/Akt and AMPK signaling pathways. PLoS One 9: e99631, 2014.

20. Ozturk G, Ginis Z, Akyol S, Erden G, Gurel A and Akyol O: The anticancer mechanism of caffeic acid phenethyl ester (CAPE): Review of melanomas, lung and prostate cancers. Eur Rev Med Pharmacol Sci 16: 2064-2068, 2012.

21. Chung TW, Moon SK, Chang YC, Ko JH, Lee YC, Cho G, Kim SH, Kim JG and Kim CH: Novel and therapeutic effect of caffeic acid and caffeic acid phenyl ester on hepatocarcinoma cells: Complete regression of hepatoma growth and metastasis by dual mechanism. FASEB J 18: 1670-1681, 2004.

22. Shi ZH, Li NG, Shi QP, Tang H, Tang YP, Li W, Yin L, Yang JP and Duan JA: Synthesis and structure-activity relationship analysis of caffeic acid amides as selective matrix metalloproteinase inhibitors. Bioorg Med Chem Lett 23: 1206-1211, 2013.

23. Stupp R, Mason WP, van den Bent MJ, Weller M, Fisher B, Taphoorn MJ, Belanger K, Brandes AA, Marosi C, Bogdahn U, et al: Radiotherapy plus concomitant and adjuvant temozolomide for glioblastoma. N Engl J Med 352: 987-996, 2005.

24. Villano JL, Seery TE and Bressler LR: Temozolomide in malignant gliomas: Current use and future targets. Cancer Chemother Pharmacol 64: 647-655, 2009.

25. Wait SD, Prabhu RS, Burri SH, Atkins TG and Asher AL: Polymeric drug delivery for the treatment of glioblastoma. Neuro Oncol 17 (Suppl 2): ii9-ii23, 2015.

26. Davies KJ: The complex Interaction of matrix metalloproteinases in the migration of cancer cells through breast tissue stroma. Int J Breast Cancer 2014: 839094, 2014.

27. Könnecke $H$ and Bechmann I: The role of microglia and matrix metalloproteinases involvement in neuroinflammation and gliomas. Clin Dev Immunol 2013: 914104, 2013. 